\title{
Noninvasive Respiratory Support in Acute Hypoxemic Respiratory Failure
}

\author{
Thomas Piraino
}

\author{
Introduction \\ Review of the Evidence \\ Systematic Review and Meta-Analyses \\ Clinical Practice Guidelines \\ Patient Selection \\ When Benefit Is Known \\ When Benefit Is Less Clear \\ Risk Factors for NIV Failing \\ $\mathbf{P}_{\mathrm{aO}_{2}} / \mathrm{F}_{\mathrm{IO}_{2}}$ \\ Severity Scores \\ Tidal Volume \\ Community Acquired Pneumonia \\ Acute Respiratory Distress Syndrome \\ Immunosuppression \\ Combined Factors: The HACOR Score \\ Risk of Higher Mortality \\ NIV Failure \\ Delaying Intubation \\ NIV Settings and Equipment \\ The Role of HFNC \\ Summary
}

For more than 40 years, noninvasive ventilation has been the first-line preferred therapy for acute-on-chronic conditions, such as COPD and cardiogenic pulmonary edema. The use of noninvasive ventilation in the treatment of hypoxemic respiratory failure, however, has been met with mixed results associated with higher risks of intubation (failure of therapy) and with higher risks of mortality. The purpose of this review was to describe the current evidence and important considerations when patients with hypoxemic respiratory failure are managed with noninvasive ventilation. Key words: acute hypoxemic respiratory failure; high-flow nasal cannula; noninvasive ventilation. [Respir Care 2019;64(6):638-646. () 2019 Daedalus Enterprises]

\section{Introduction}

Acute hypoxemic respiratory failure usually refers to a patient with an increased breathing frequency and low

\footnotetext{
Mr Piraino is affiliated with St Michael's Hospital, Toronto, Ontario, Canada.

Mr Piraino presented a version of this paper at the 57th RESPIRATORY CARE Journal Conference, Noninvasive Respiratory Support in Adults, held June 14-15, 2018, in St Petersburg, Florida.
}

Mr Piraino has disclosed relationships with Dräger and Philips. oxygen saturation or $\mathrm{P}_{\mathrm{aO}_{2}} / \mathrm{F}_{\mathrm{IO}_{2}}$ while receiving supplemental oxygen (eg, breathing frequency of $>25$ breaths $/ \mathrm{min}$ with a $\mathrm{P}_{\mathrm{aO}_{2}} / \mathrm{F}_{\mathrm{IO}_{2}}$ of $\leq 300 \mathrm{~mm} \mathrm{Hg}$ ). It can have many causes, and the use of noninvasive ventilation (NIV) in

\footnotetext{
Correspondence: Thomas Piraino RRT FCSRT, St. Michael's Hospital, 30 Bond Street, Toronto, Ontario M5B 1W8, Canada. E-mail: thomaspiraino@gmail.com.
}

DOI: $10.4187 /$ respcare. 06735 


\section{Noninvasive Respiratory Support in Acute Hypoxemic Respiratory Failure}

these patients requires a deep understanding of available data to determine the appropriateness of use. Patient selection should involve a cautious approach, with knowledge of the risk factors associated with NIV failure. This review described the evidence related to the treatment of acute hypoxemic respiratory failure with NIV and considerations related to patient selection, risk factors, and interface options, including the use of high-flow nasal cannula (HFNC). For the purpose of this article, NIV refers to bi-level positive airway pressure; otherwise, continuous positive airway pressure is referred to as CPAP.

\section{Review of the Evidence}

NIV has long been known as an effective treatment for acute hypercapnic respiratory failure secondary to COPD. ${ }^{1}$ However, the use of NIV as a general approach to managing respiratory failure in the absence of hypercapnia has shown mixed results in the literature, particularly in patients with hypoxemic respiratory failure. In 1995, Wysocki et $\mathrm{al}^{2}$ were one of the first groups to evaluate the effects of NIV in subjects without hypercapnia, and they found no benefit. Specific etiologies have since been studied, such as acute cardiogenic pulmonary edema, immunosuppression, postoperative management, community-acquired pneumonia (CAP), postextubation management, and acute lung injury and ARDS, with mixed results..$^{3-11}$ Despite the exponential growth in publications about NIV in the past 40 years, many of the studies were small and included a wide variety of etiologies of respiratory failure. When these relatively small studies were grouped together into a systematic review or meta-analysis, the underlying difference among the causes of acute hypoxemic respiratory failure resulted in significant heterogeneity. ${ }^{12-15}$

\section{Systematic Review and Meta-Analyses}

In 2004 Keenan et al ${ }^{12}$ published one of the earliest systematic reviews that assessed the use of NIV for hypoxemic respiratory failure. They found that there seemed to be a benefit for reducing endotracheal intubation, ICU length of stay, and mortality. However, many of the studies included subjects with mixed etiologies: some who would likely benefit from NIV and others who would not. The heterogeneity among studies precluded any recommendation for the routine use of NIV in patients with acute hypoxemic respiratory failure. In 2017, the same conclusion persisted in a meta-analysis published by $\mathrm{Xu}$ et al. ${ }^{14}$ Despite mentions of potential benefits when using NIV in the management of acute hypoxemic respiratory failure, there was insufficient evidence to recommend its generalized use outside of a clinical trial. ${ }^{12,14}$
Table 1. Current Guidelines for Adult Noninvasive Ventilation

\begin{tabular}{|c|c|c|}
\hline Patient Category & Recommendation & $\begin{array}{l}\text { Certainty } \\
\text { of Evidence }\end{array}$ \\
\hline Hypercapnic COPD exacerbation & Do it* & High \\
\hline Cardiogenic pulmonary edema & Do it* & Moderate \\
\hline Postoperative patients & Do it & Moderate \\
\hline Palliative care & Do it & Moderate \\
\hline Immunocompromised & Do it & Moderate \\
\hline $\begin{array}{l}\text { Postextubation in patients at } \\
\text { high risk }\end{array}$ & Do it & Low \\
\hline Trauma & Do it & Moderate \\
\hline $\begin{array}{l}\text { Weaning patients who are } \\
\text { hypercapnic }\end{array}$ & Do it & Moderate \\
\hline $\begin{array}{l}\text { Prevention of hypercapnia } \\
\text { COPD exacerbation }\end{array}$ & Do not do it & Low \\
\hline Postextubation respiratory failure & Do not do it & Low \\
\hline Acute asthma exacerbation & No recommendation & \\
\hline De novo respiratory failure & No recommendation & \\
\hline Pandemic viral illness & No recommendation & \\
\hline \multicolumn{3}{|c|}{$\begin{array}{l}\text { * Indicates a strong recommendation, all other recommendations (for or against) are } \\
\text { conditional; further evidence may impact the certainty of effect for conditional } \\
\text { recommendations (From Reference 13). }\end{array}$} \\
\hline
\end{tabular}

\section{Clinical Practice Guidelines}

Clinical practice guidelines are developed by using a systematic approach to review the available evidence and come to a decision on whether the evidence supports the use of a therapy for a specific group of patients. In 2011, the Canadian Critical Care Trials Group published clinical practice guidelines for the use of NIV. ${ }^{15}$ In these guidelines, a variety of patient populations and clinical scenarios were addressed and recommendations for or against the use of NIV were provided. ${ }^{15}$ The most recent clinical practice guidelines were published as a joint effort by the American Thoracic Society and the European Respiratory Society. ${ }^{13}$ Many of the recommendations (for and against using NIV) were similar (or unchanged) from the previous Canadian Critical Care Trials Group guidelines, ${ }^{15}$ with the addition of some specific clinical scenarios. A summary of the recent recommendations is provided in Table 1.

The American Thoracic Society/European Respiratory Society guidelines ${ }^{13}$ provide no recommendation for the use of NIV in the management of de novo hypoxemic respiratory failure. The term de novo hypoxemic respiratory failure refers to acute hypoxemic respiratory failure in the absence of underlying chronic lung disease or cardiac failure. These patients generally have $\mathrm{P}_{\mathrm{aO}_{2}} / \mathrm{F}_{\mathrm{IO}_{2}} \leq 200$ $\mathrm{mm} \mathrm{Hg}$, and breathing frequencies $>30 \mathrm{breaths} / \mathrm{min}$, and could involve many potential causes of acute hypoxemic respiratory failure (eg, sepsis, atelectasis, pneumonia). The goal of NIV is to reduce the work of breathing while improving gas exchange for the purpose of avoiding intu- 
bation. Although NIV can reduce the work of breathing in acute lung injury $\left(\mathrm{P}_{\mathrm{aO}_{2}} / \mathrm{F}_{\mathrm{IO}_{2}} 200-300\right) \mathrm{mm} \mathrm{Hg}$, it may require a significant amount of inspiratory pressure. This introduces other issues with interface leakage, patient tolerance, excessive transpulmonary pressure, and, possibly, excessive tidal volume. ${ }^{16,17}$ These combined issues may contribute to the overall poor outcomes when NIV has been studied in this population. ${ }^{18}$

\section{Patient Selection}

\section{When Benefit Is Known}

There are groups of patients mentioned in the current guidelines that typically present with acute hypoxemic respiratory failure and the benefits of NIV are known. ${ }^{13}$ These include cardiogenic pulmonary edema, postoperative patients, and trauma patients. The recommendation for treating cardiogenic pulmonary edema is strong but with a moderate level of evidence. ${ }^{13}$ The largest study to date found no difference in the intubation rate or mortality when comparing NIV, CPAP, or standard oxygen therapy. ${ }^{3}$ However, there was a large degree of crossover from standard oxygen therapy to NIV that could make interpretation difficult. This study has been combined with smaller studies in a Cochrane Review that found significantly reduced hospital mortality and less need for intubation. ${ }^{19}$ The strength of evidence is due to many small studies, and more, larger studies would be beneficial. The available evidence does not suggest a benefit of NIV over CPAP; the goal should be to decrease work of breathing with either mode.

The certainty of evidence for using NIV in the postoperative setting is moderate for specific patients after lung resection and after abdominal surgery. ${ }^{5,11}$ Lung resection subjects had a significantly reduced need for intubation and hospital mortality, whereas subjects after abdominal surgery had significantly lower intubation rates with NIV and lower (but not significant) 90-d mortality. ${ }^{13}$ In trauma patients, the recommendation is a result of combining data from the few small randomized controlled trials available, and it is specific to patients with chest trauma. The pooled analysis found lower intubation rates, lower mortality, less nosocomial pneumonia, and a shorter ICU length of stay when using NIV. ${ }^{13}$ Similar to cardiogenic pulmonary edema, whether NIV or CPAP should be used in this population is less clear.

\section{When Benefit Is Less Clear}

Delivering NIV to patients in acute hypoxemic respiratory failure is associated with both benefits and risks. The risk of NIV failing in patients with acute hypoxemic respiratory failure is well described in the literature, and there is a large range of reported failure rates, between 25 and $87 \%$. When NIV is successfully used to treat acute hypoxemic respiratory failure, there is a reduction in mortality. However, the risks of NIV failing are different for patients with de novo respiratory failure. Therefore, clinicians should take a judicious approach when choosing NIV to treat acute hypoxemic respiratory failure. The way to properly select patients for NIV and determine when therapy is failing relies on the use of established risk variables available in the literature. In the following sections, clinical findings associated with NIV failure and increased risk of mortality will be discussed.

\section{Risk Factors for NIV Failing}

$\mathbf{P}_{\mathrm{aO}_{2}} / \mathrm{F}_{\mathrm{IO}_{2}}$

The $\mathrm{P}_{\mathrm{aO}} / \mathrm{F}_{\mathrm{IO}_{2}}$ is probably one of the most commonly used variables to quantify the degree of hypoxemia because it takes into consideration the level of $\mathrm{F}_{\mathrm{IO}_{2}}$ required to achieve the arterial oxygen level. It has also been one of the key components for defining and classifying ARDS. ${ }^{20}$ In addition, it is simple to determine with the collection of an arterial blood gas sample. As expected, the more severe (lower) a patient's $\mathrm{P}_{\mathrm{aO}} / \mathrm{F}_{\mathrm{IO}}$, the higher the risk he or she has of NIV failing. Most studies found through multivariate analyses that a $\mathrm{P}_{\mathrm{aO}_{2}} / \mathrm{F}_{\mathrm{IO}_{2}}<150 \mathrm{~mm} \mathrm{Hg}$ at baseline and up to $1 \mathrm{~h}$ after NIV initiation predicts NIV failure. ${ }^{21-24} \mathrm{In}$ addition, a more recent study found a $\mathrm{P}_{\mathrm{aO}_{2}} / \mathrm{F}_{\mathrm{IO}_{2}}$ of $<200 \mathrm{~mm} \mathrm{Hg}$ to also be predictive of failure, particularly in acute hypoxemic respiratory failure in subjects treated with NIV. ${ }^{25}$

\section{Severity Scores}

There are several severity scores available to clinicians to assess the overall condition of the patient. A variety of physiologic values are used to calculate these scores, and they usually correlate with a potential risk of mortality. The most common scores used in studies of NIV include the Simplified Acute Physiology Score II, Sequential Organ Failure Assessment score, and Acute Physiology and Chronic Health Evaluation II score. As expected, the higher the severity score, the higher the risk of poor outcomes. Some of these severity scores have been tested in multivariate analyses with various cutoff points for predicting not only NIV failure but also mortality. ${ }^{21,22,24,26}$ The various cutoff values for the Simplified Acute Physiology Score II and Sequential Organ Failure Assessment score are included in Table 2. Clinicians should also be conscious of the presence of septic shock because septic shock and also the use of vasoactive drugs are associated with failure of NIV. ${ }^{21,24}$ 


\section{Noninvasive Respiratory Support in Acute Hypoxemic Respiratory Failure}

Table 2. Risk Factors and Mortality Risk Associated With NIV

\begin{tabular}{|c|c|c|}
\hline Parameter & Value & Reference(s) \\
\hline \multicolumn{3}{|l|}{ Risk factor } \\
\hline $\mathrm{P}_{\mathrm{aO}_{2}} / \mathrm{F}_{\mathrm{IO}_{2}}, \mathrm{~mm} \mathrm{Hg}$ & $<150$ & Antonelli et al, ${ }^{21}$ Bellani et al, ${ }^{23}$ Carrillo et al, ${ }^{24}$ Demoule et al ${ }^{22}$ \\
\hline Severity scores & SAPS II $\geq 35$, SOFA $\geq 7$, APACHE II* & Antonelli et al ${ }^{21}$ Carrillo et al ${ }^{24}$ \\
\hline Tidal volume, $\mathrm{mL} / \mathrm{kg}$ & $>9$ & Carteaux et $\mathrm{al}^{, 28}$ Frat et $\mathrm{al}^{25}$ \\
\hline Age, y & $>40$ & Antonelli et $\mathrm{al}^{21}$ \\
\hline Etiology & CAP, ARDS, immunosuppression & Antonelli et al, ${ }^{21}$ Bellani et al, ${ }^{23}$ Demoule et al, ${ }^{22}$ Carteaux et al ${ }^{28}$ \\
\hline Score & $\mathrm{HACOR}>5$ & Duan et $\mathrm{al}^{34}$ \\
\hline \multicolumn{3}{|l|}{ Mortality risk } \\
\hline Severity scores & SAPS II $>47$, SOFA $\geq 12$, APACHE II $\dagger$ & Carrillo et al, ${ }^{24}$ Demoule et al ${ }^{22}$ \\
\hline Delayed intubation & $>12 \mathrm{~h}$ & Duan et $\mathrm{al}^{34}$ \\
\hline NIV failure & Required intubation & Rodriguez et al, ${ }^{35}$ Duan et al, ${ }^{34}$ Demoule et al ${ }^{22}$ \\
\hline Score & $\mathrm{HACOR}>5$ & Duan et $\mathrm{al}^{34}$ \\
\hline Age, y & $>64$ y & Demoule et $\mathrm{al}^{22}$ \\
\hline $\begin{array}{l}\text { * Median } 14 \text { vs } 17 \text { (success vs fa } \\
\dagger \text { Median } 15 \text { vs } 19 \text { (survivors vs } \\
\text { NIV = noninvasive ventilation } \\
\text { SAPS = Simplified Acute Physi } \\
\text { SOFA = Sequential Organ Failur } \\
\text { APACHE = Acute Physiology ar } \\
\text { CAP = community-acquired pnet } \\
\text { HACOR = heart rate, acidosis, c }\end{array}$ & $\begin{array}{l}\text { lors). } \\
\text { ore } \\
\text { nent } \\
\text { c Health Evaluation } \\
\text { less, oxygenation, and respiratory rate }\end{array}$ & \\
\hline
\end{tabular}

\section{Tidal Volume}

Although many standalone NIV devices use a singlelimb-type circuit, many ventilators that use dual-limb circuits in the ICU can deliver NIV with the ability to measure exhaled tidal volume. Devices that use single-limb circuits may be able to estimate exhaled volume but may be less accurate in the presence of significant leaks. ${ }^{27} \mathrm{Re}$ cent studies looked at the ability of exhaled tidal volume to predict failure of NIV in subjects with de novo acute hypoxemic respiratory failure. ${ }^{28,29} \mathrm{In}$ a study that targeted an exhaled tidal volume of $6-8 \mathrm{~mL} / \mathrm{kg}$ of predicted body weight, the researchers found that an exhaled tidal volume of $>9.5 \mathrm{~mL} / \mathrm{kg}$ of predicted body weight predicted NIV failure with a sensitivity and specificity of $82 \%$ and $87 \%$, respectively. ${ }^{28}$

A post hoc analysis of the FLORALI study ${ }^{29}$ found that a tidal volume $>9 \mathrm{~mL} / \mathrm{kg}$ of predicted body weight at $1 \mathrm{~h}$ was associated with the need for intubation. ${ }^{25}$ However, the tidal volume range permitted in the FLORALI study was $7-10 \mathrm{~mL} / \mathrm{kg}$ of predicted body weight, which allowed (by protocol design) delivery of tidal volume now found to be associated with NIV failure. Despite these differences in tidal volume $(6-8 \mathrm{~mL} / \mathrm{kg} \text { vs. } 7-10 \mathrm{~mL} / \mathrm{kg})^{28,29}$ a similar level of tidal volume was found to be associated with NIV failure. This may be due to the difficulty in controlling the underlying respiratory drive of patients in acute hypoxemic respiratory failure. Further prospective studies that control tidal volume are needed to confirm if this is a useful target to prevent NIV failure.

\section{Community Acquired Pneumonia}

None of the guidelines for NIV includes a recommendation for treating CAP. Many of the earlier studies had mixed subject types with mixed results and high failure rates. ${ }^{18}$ In addition, pneumonia as the etiology of respiratory failure is independently associated with the risk of NIV failing. ${ }^{21}$ Patients with pneumonia share the same risk factors as other patients with acute hypoxemic respiratory failure but are also at risk of NIV failing if the infiltrates found on chest radiograph worsen in the $24 \mathrm{~h}$ after treatment with NIV. ${ }^{24}$ Furthermore, delaying intubation in patients with pneumonia who are being treated with NIV increases the risk of mortality in de novo respiratory failure. ${ }^{23}$ The ability to successfully treat a patient with pneumonia that does not have underlying acute-on-chronic respiratory failure requires careful attention to risk factors of failure and an experienced team of health-care providers. ${ }^{18}$ The literature has been consistent over the years, patients without underlying cardiac or respiratory disease are at a higher risk of NIV failing when being treated for acute hypoxemic respiratory failure.

\section{Acute Respiratory Distress Syndrome}

The group of investigators behind the LUNG SAFE study published evidence that NIV is commonly used in patients who meet criteria for ARDS. ${ }^{23,30}$ As expected, increasing ARDS severity (measured by $\mathrm{P}_{\mathrm{aO}_{2}} / \mathrm{F}_{\mathrm{IO}_{2}}$ ) resulted in an increased risk of NIV failure. ${ }^{23}$ Subjects 
with $\mathrm{P}_{\mathrm{aO}_{2}} / \mathrm{F}_{\mathrm{IO}_{2}}<150 \mathrm{~mm} \mathrm{Hg}$ had higher ICU mortality when treated with NIV compared with subjects treated with invasive ventilation. ${ }^{23}$

The most common NIV interface used in clinical practice to treat acute hypoxemic respiratory failure is an oronasal mask (which covers the mouth and nose). A recent randomized controlled trial ${ }^{9}$ that compared the helmet device with the oronasal mask in subjects with ARDS demonstrated a significant reduction in intubation rates and mortality when a helmet interface was used. Helmet devices are unique and require the use of equipment capable of delivering higher flows to ensure proper washout of exhaled $\mathrm{CO}_{2}$ and a clinical team familiar with the nuances of its use. The reasons for improved outcomes could be related to the ability to deliver and maintain higher levels of PEEP, improved patient tolerance, or longer sessions of NIV, but further data are required to confirm these results.

\section{Immunosuppression}

For patients with immunosuppression and who present with respiratory failure, clinical guidelines have recommended using NIV as a preference over invasive ventilation. ${ }^{13,15}$ However, in subjects with de novo respiratory failure, immunosuppression has been associated with a risk of NIV therapy failing. ${ }^{22,25,28}$ Data have been published in subjects with immunosuppression and respiratory failure treated with HFNC, which demonstrate that HFNC may be preferred instead of NIV for patients with immunosuppression. ${ }^{31,32}$ However, HFNC may not have the additional benefit over standard oxygen therapy. ${ }^{33}$

\section{Combined Factors: The HACOR Score}

By using common risk factors already found in the literature, Duan et al ${ }^{34}$ tested and validated a score that uses heart rate, acidosis, consciousness, oxygenation, and RR (HACOR) (Table 3). A HACOR score of $>5$ after $1 \mathrm{~h}$ of NIV treatment had a diagnostic accuracy to predict NIV failure of $81.8 \%$ in their testing cohort and $86 \%$ in their validation cohort. Subjects with a HACOR score $>5$ at $1 \mathrm{~h}$ also had higher hospital mortality than subjects with a HACOR score $\leq 5$ (65.2\% and $21.6 \%$, respectively). ${ }^{34}$ This was a single-center study and needs further testing to confirm its external validity. Furthermore, many values in the score would individually meet the criteria for intubation, despite the score of other values. A scoring system that uses less-obvious or less-severe criteria to predict failure might be more beneficial at aiding clinical decisions when uncertainty is present.
Table 3. HACOR Score

\begin{tabular}{|c|c|}
\hline Parameter & HACOR Score \\
\hline \multicolumn{2}{|l|}{ Heart rate } \\
\hline$\leq 120$ beats $/ \mathrm{min}$ & 0 \\
\hline$\geq 121$ beats $/ \mathrm{min}$ & 1 \\
\hline \multicolumn{2}{|l|}{$\mathrm{pH}$} \\
\hline$\geq 7.35$ & 0 \\
\hline $7.30-7.34$ & 2 \\
\hline $7.25-7.29$ & 3 \\
\hline$<7.25$ & 4 \\
\hline \multicolumn{2}{|c|}{ Glasgow coma scale score } \\
\hline 15 & 0 \\
\hline $13-14$ & 2 \\
\hline $11-12$ & 5 \\
\hline$\leq 10$ & 10 \\
\hline \multicolumn{2}{|l|}{$\mathrm{P}_{\mathrm{aO}_{2}} / \mathrm{F}_{\mathrm{IO}_{2}}$} \\
\hline$\geq 201 \mathrm{~mm} \mathrm{Hg}$ & 0 \\
\hline 176-200 mm Hg & 2 \\
\hline $151-175 \mathrm{~mm} \mathrm{Hg}$ & 3 \\
\hline $126-150 \mathrm{~mm} \mathrm{Hg}$ & 4 \\
\hline $101-125 \mathrm{~mm} \mathrm{Hg}$ & 5 \\
\hline$\leq 100 \mathrm{~mm} \mathrm{Hg}$ & 6 \\
\hline \multicolumn{2}{|l|}{ Frequency } \\
\hline$\leq 30$ breaths/min & 0 \\
\hline $31-35$ breaths/min & 1 \\
\hline $36-40$ breaths/min & 2 \\
\hline $41-45$ breaths/min & 3 \\
\hline$\geq 46$ breaths/min & 4 \\
\hline \multicolumn{2}{|c|}{$\begin{array}{l}\text { When receiving NIV for hypoxemic respiratory failure, a HACOR score of }>5 \text { at } 1 \mathrm{~h} \text { of NIV } \\
\text { predicted failure. } \\
\text { HACOR = heart rate, acidosis, consciousness, oxygenation, and respiratory rate } \\
\text { NIV = noninvasive ventilation }\end{array}$} \\
\hline
\end{tabular}

\section{Risk of Higher Mortality}

\section{NIV Failure}

Closely monitoring patients with acute hypoxemic respiratory failure who were treated with NIV is important because failure is associated with an increased risk of mortality. ${ }^{22,34,35}$ This risk of mortality when NIV fails in a patient does not seem to be the same for a patient with acute-on-chronic respiratory failure. ${ }^{22}$ Although patients with higher severity scores may be at higher risk of NIV failure and, therefore, would have a higher rate of mortality, NIV failure has been established as an independent risk factor for mortality.

\section{Delaying Intubation}

Another finding of the HACOR article was that, when subjects met the cutoff HACOR score of $>5$ at $1 \mathrm{~h}$ if they were intubated $>12 \mathrm{~h}$ after starting NIV, then they had significantly higher mortality than those who were intu- 
bated before $12 \mathrm{~h}$ of therapy. ${ }^{34}$ The subjects in the HACOR study had de novo acute hypoxemic respiratory failure of various etiologies. ${ }^{34}$ In subjects with CAP as the underlying cause of respiratory failure, delaying intubation beyond $3 \mathrm{~d}$ was associated with a lower chance of survival. ${ }^{24,36}$ Careful attention to patient selection and monitoring for risk factors of NIV failure should be a priority when any patient is being treated with a therapy that lacks a solid evidence base for its use. There is evidence that NIV for acute hypoxemic respiratory failure has the potential to be beneficial, but the fact that there is significant potential for harm requires these patients to be monitored closely to avoid delaying intubation.

\section{NIV Settings and Equipment}

Another key element of NIV therapy that is not addressed in the clinical practice guidelines is device settings. Although the lack of setting recommendations could be taken as positive because therapy should be individualized, this leaves clinicians the freedom to choose settings that may, on the surface, improve physiologic variables, for example, oxygenation, but may negatively impact the tolerance of therapy. In addition, clinicians need to be aware that there are differences between NIV devices regarding the inspiratory pressure; ICU ventilators normally provide pressure relative to the expiratory pressure ( $\Delta$ pressure), whereas standalone devices normally provide pressure relative to atmosphere (absolute pressure). The application of higher expiratory positive airway pressure (EPAP/PEEP) may improve oxygenation in a patient with acute lung injury, but this may result in increasing leaks when the inspiratory positive airway pressure is elevated. ${ }^{16}$ Dyspnea is best relieved with a sufficient support level above EPAP/PEEP (inspiratory positive airway pressure minus EPAP/PEEP), and finding the ideal balance between support and EPAP can be challenging. For these reasons, the upper limit of EPAP/PEEP in most studies of NIV, particularly those that involve acute hypoxemic respiratory failure, is no higher than $10 \mathrm{~cm} \mathrm{H}_{2} \mathrm{O}$. As mentioned previously, the ability to maintain higher levels of PEEP with the helmet interface may have contributed to the surprising outcomes, ${ }^{9}$ but further data are needed to confirm this.

Currently, the primary options for NIV delivery in the acute environment include standalone devices, transport ventilators, and ICU ventilators. A device dedicated to the delivery of NIV (standalone) may provide the most synchronous delivery of NIV, and this aspect is important. ${ }^{37}$ Alternatively, when standalone devices are not readily available, ICU and transport ventilators with NIV algorithms can effectively deliver NIV therapy. An important aspect of NIV delivery is patient comfort and tolerance of therapy. There is controversy regarding the use of humid- ification due to the typically short duration of NIV therapy required in some patients. Humidification has been shown to improve comfort and tolerance of therapy, and may play an important role in tolerance of therapy when the underlying cause of respiratory failure is not known or is not rapidly reversible. ${ }^{38,39}$ Once delivery of NIV has started, the optimal dosage in terms of duration of sessions is still not certain. Whether longer sessions of NIV with short breaks are better than shorter periods with multiple breaks (but with similar daily totals) has not been a primary focus of any prospective trial to date.

\section{The Role of HFNC}

The more recent evidence regarding HFNC involves devices that deliver air-oxygen mixtures at flows up to $60 \mathrm{~L} / \mathrm{min}$. To deliver gas at this flow requires conditioning (ie, heating), the gas for patient comfort. The use of HFNC in the management of acute hypoxemic respiratory failure has gained tremendous popularity after the paper by Frat et al ${ }^{29}$ in 2015: the FLORALI study. They compared the use of HFNC, NIV, and standard oxygen therapy in subjects with acute hypoxemic respiratory failure. Patients with hypercapnic respiratory failure were excluded. Although the primary outcome (ie, the need for intubation) was not significantly different for the entire study population $\left(\mathrm{P}_{\mathrm{aO}_{2}} / \mathrm{F}_{\mathrm{IO}_{2}}<\right.$ $300 \mathrm{~mm} \mathrm{Hg}$ ), the secondary outcome of 90-d mortality was lower in the subjects treated with HFNC. The lower mortality in subjects with an HFNC was likely because the subgroup of subjects with a $\mathrm{P}_{\mathrm{aO}} / \mathrm{F}_{\mathrm{IO}_{2}}<200 \mathrm{~mm} \mathrm{Hg} \mathrm{had}$ significantly lower intubation rates. It is worth noting that, although there currently is no recommendation for NIV specifically in the treatment of CAP, it was the mostcommon reason for respiratory failure in the FLORALI trial. Further studies are required to determine if HFNC is, in fact, the ideal treatment strategy for patients with CAP.

The use of HFNC has also been studied in the emergency department to treat patients with acute respiratory failure (not specifically hypoxemic respiratory failure). A study by Jones et $\mathrm{al}^{40}$ randomized 303 subjects to receive HFNC or standard oxygen therapy and found less need for escalation of therapy within $24 \mathrm{~h}$, but this was not statistically significant. Doshi et $\mathrm{al}^{41}$ published a randomized noninferiority trial of 204 subjects that compared HFNC with NIV and found HFNC to be noninferior for the treatment of acute respiratory failure. However, in this study, there was a significant amount of crossover from HFNC to NIV (23/104 [22\%]). In the subjects who crossed over to NIV, $87 \%$ (20/23) avoided intubation by being treated with NIV.41 The results of this trial would have been significantly different if crossover was not allowed. Currently, there is insufficient evidence to support using HFNC instead of NIV to treat all forms of respiratory failure. The current guidelines are based on the available evidence, and, the use of 


\section{Noninvasive Respiratory Support in Acute Hypoxemic Respiratory Failure}

HFNC for conditions when NIV is currently recommended should only be done in the context of a clinical trial.

The treatment of patients who are immunosuppressed is an area in which HFNC may be impacting the current guidelines (conditional recommendation with a moderate certainty of evidence). ${ }^{31,32}$ A post hoc analysis of the FLORALI trial demonstrated that subjects with immunosuppression had better outcomes (lower intubation and lower mortality) when randomized to HFNC than those randomized to NIV. ${ }^{32}$ An observational cohort study also found that NIV used as a first-line therapy in subjects who were immunosuppressed was independently associated with worse outcomes (higher intubation and higher mortality) compared with those treated with HFNC. ${ }^{31}$ There are a number of physiologic benefits for the use of HFNC described in the literature, including reduced breathing frequency and the work of breathing, flushing of anatomic dead space, improved tolerance of therapy, and the humidification of airways. ${ }^{42-44}$ The literature most certainly will describe an increasingly diverse group of patients for which HFNC may benefit, as evident by the current rate of publications on the subject.

\section{Summary}

The use of NIV in the general management of acute hypoxemic respiratory failure lacks clinical practice guidelines, particularly in the presence of de novo respiratory failure. Although there is potential to avoid intubation in these patients by using NIV, the wide range of failure rates precludes NIV as a viable first-line therapy. If experienced clinicians choose to manage a patient in acute hypoxemic respiratory failure with NIV, then risk factors need to be observed. The use of HFNC has an increasing amount of supportive data, particularly in patients when NIV recommendations are lacking. Further data are needed to confirm the role of HFNC in patients with acute-on-chronic respiratory failure, although it seems safe and may be more effective than NIV in the management of acute hypoxemic respiratory failure and patients who are immunosuppressed.

\section{REFERENCES}

1. Brochard L, Mancebo J, Wysocki M, Lofaso F, Conti G, Rauss A, et al. Noninvasive ventilation for acute exacerbations of chronic obstructive pulmonary disease. N Engl J Med 1995;333(13):817-822.

2. Wysocki M, Tric L, Wolff MA, Millet H, Herman B. Noninvasive pressure support ventilation in patients with acute respiratory failure. A randomized comparison with conventional therapy. Chest 1995; 107(3):761-768.

3. Gray A, Goodacre S, Newby DE, Masson M, Sampson F, Nicholl J, $3 \mathrm{CPO}$ Trialists. Noninvasive ventilation in acute cardiogenic pulmonary edema. N Engl J Med 2008;359(2):142-151.

4. Hilbert G, Gruson D, Vargas F, Valentino R, Gbikpi-Benissan G, Dupon M, et al. Noninvasive ventilation in immunosuppressed patients with pulmonary infiltrates, fever, and acute respiratory failure. N Engl J Med 2001;344(7):481-487.
5. Jaber S, Lescot T, Futier E, Paugam-Burtz C, Seguin P, Ferrandiere M, et al.; NIVAS Study Group. Effect of noninvasive ventilation on tracheal reintubation among patients with hypoxemic respiratory failure following abdominal surgery: a randomized clinical trial. JAMA 2016;315(13):1345-1353.

6. Confalonieri M, Potena A, Carbone G, Porta RD, Tolley EA, Umberto Meduri G. Acute respiratory failure in patients with severe community-acquired pneumonia. A prospective randomized evaluation of noninvasive ventilation. Am J Respir Crit Care Med 1999; 160(5 Pt 1):1585-1591.

7. Esteban A, Frutos-Vivar F, Ferguson ND, Arabi Y, Apezteguía C, González M, et al. Noninvasive positive-pressure ventilation for respiratory failure after extubation. N Engl J Med 2004;350(24):24522460.

8. Zhan Q, Sun B, Liang L, Yan X, Zhang L, Yang J, et al. Early use of noninvasive positive pressure ventilation for acute lung injury: a multicenter randomized controlled trial. Crit Care Med 2012;40(2): 455-460.

9. Patel BK, Wolfe KS, Pohlman AS, Hall JB, Kress JP. Effect of noninvasive ventilation delivered by helmet vs face mask on the rate of endotracheal intubation in patients with acute respiratory distress syndrome: a randomized clinical trial. JAMA 2016;315(22):24352441.

10. Girault C, Daudenthun I, Chevron V, Tamion F, Leroy J, Bonmarchand G. Noninvasive ventilation as a systematic extubation and weaning technique in acute-on-chronic respiratory failure: a prospective, randomized controlled study. Am J Respir Crit Care Med 1999; 160(1):86-92.

11. Auriant I, Jallot A, Hervé P, Cerrina J, Le Roy Ladurie F, Fournier $\mathrm{JL}$, et al. Noninvasive ventilation reduces mortality in acute respiratory failure following lung resection. Am J Respir Crit Care Med 2001;164(7):1231-1235.

12. Keenan SP, Sinuff T, Cook DJ, Hill NS. Does noninvasive positive pressure ventilation improve outcome in acute hypoxemic respiratory failure? A systematic review. Crit Care Med 2004;32(12):25162523.

13. Rochwerg B, Brochard L, Elliott MW, Hess D, Hill NS, Nava S, et al.; Raoof S Members of the Task Force. Official ERS/ATS clinical practice guidelines: noninvasive ventilation for acute respiratory failure. Eur Respir J 2017;50(2). pii: 1602426.

14. Xu XP, Zhang XC, Hu SL, Xu JY, Xie JF, Liu SQ, et al. Noninvasive ventilation in acute hypoxemic nonhypercapnic respiratory failure: a systematic review and meta-analysis. Crit Care Med 2017; 45(7):e727-e733.

15. Keenan SP, Sinuff T, Burns KE, Muscedere J, Kutsogiannis J, Mehta S, et al.; Canadian Critical Care Trials Group/Canadian Critical Care Society Noninvasive Ventilation Guidelines Group. Clinical practice guidelines for the use of noninvasive positive-pressure ventilation and noninvasive continuous positive airway pressure in the acute care setting. CMAJ 2011;183(3):E195-E214.

16. L'Her E, Deye N, Lellouche F, Taille S, Demoule A, Fraticelli A, et al. Physiologic effects of noninvasive ventilation during acute lung injury. Am J Respir Crit Care Med 2005;172(9):1112-1118.

17. Kallet RH, Diaz JV. The physiologic effects of noninvasive ventilation. Respir Care 2009;54(1):102-115.

18. Brochard L, Lefebvre JC, Cordioli RL, Akoumianaki E, Richard JC. Noninvasive ventilation for patients with hypoxemic acute respiratory failure. Semin Respir Crit Care Med 2014;35(4):492-500.

19. Vital FM, Ladeira MT, Atallah AN. Non-invasive positive pressure ventilation (CPAP or bilevel NPPV) for cardiogenic pulmonary oedema. Cochrane Database Syst Rev 2013;(5):CD005351.

20. ADT Definition Task Force, Ranieri VM, Rubenfeld GD, Thompson BT, Ferguson ND, Caldwell E, et al. Acute respiratory distress syndrome: the Berlin Definition. JAMA 2012;307(23):2526-2533. 


\section{Noninvasive Respiratory Support in Acute Hypoxemic Respiratory Failure}

21. Antonelli M, Conti G, Moro ML, Esquinas A, Gonzalez-Diaz G, Confalonieri M, et al. Predictors of failure of noninvasive positive pressure ventilation in patients with acute hypoxemic respiratory failure: a multi-center study. Intensive Care Med 2001;27(11):17181728.

22. Demoule A, Girou E, Richard JC, Taille S, Brochard L. Benefits and risks of success or failure of noninvasive ventilation. Intensive Care Med 2006;32(11):1756-1765.

23. Bellani G, Laffey JG, Pham T, Madotto F, Fan E, Brochard L, et al.; LUNG SAFE Investigators, ESICM Trials Group. Noninvasive ventilation of patients with acute respiratory distress syndrome. Insights from the LUNG SAFE Study. Am J Respir Crit Care Med 2017; 195(1):67-77.

24. Carrillo A, Gonzalez-Diaz G, Ferrer M, Martinez-Quintana ME, Lopez-Martinez A, Llamas N, et al. Non-invasive ventilation in community-acquired pneumonia and severe acute respiratory failure. Intensive Care Med 2012;38(3):458-466.

25. Frat JP, Ragot S, Coudroy R, Constantin JM, Girault C, Prat G, et al.; REVA network. Predictors of intubation in patients with acute hypoxemic respiratory failure treated with a noninvasive oxygenation strategy. Crit Care Med 2018;46(2):208-215.

26. Chawla R, Mansuriya J, Modi N, Pandey A, Juneja D, Chawla A, Kansal S. Acute respiratory distress syndrome: Predictors of noninvasive ventilation failure and intensive care unit mortality in clinical practice. J Crit Care 2016;31(1):26-30.

27. Ergan B, Nasilowski J, Winck JC. How should we monitor patients with acute respiratory failure treated with noninvasive ventilation? Eur Respir Rev 2018;27(148). pii: 170101

28. Carteaux G, Millán-Guilarte T, De Prost N, Razazi K, Abid S, Thille $\mathrm{AW}$, et al. Failure of noninvasive ventilation for de novo acute hypoxemic respiratory failure: role of tidal volume. Crit Care Med 2016;44(2):282-290.

29. Frat JP, Thille AW, Mercat A, Girault C, Ragot S, Perbet S, et al.; FLORALI Study Group, REVA Network. High-flow oxygen through nasal cannula in acute hypoxemic respiratory failure. N Engl J Med 2015;372(23):2185-2196.

30. Bellani G, Laffey JG, Pham T, Fan E, Brochard L, Esteban A, et al.; LUNG SAFE Investigators, ESICM Trials Group. Epidemiology, patterns of care, and mortality for patients with acute respiratory distress syndrome in intensive care units in 50 countries. JAMA 2016;315(8):788-800.

31. Coudroy R, Jamet A, Petua P, Robert R, Frat JP, Thille AW.; REVA network. High-flow nasal cannula oxygen therapy versus noninvasive ventilation in immunocompromised patients with acute respiratory failure: an observational cohort study. Ann Intensive Care 2016; 6(1):45.

32. Frat JP, Ragot S, Girault C, Perbet S, Prat G, Boulain T, et al. Effect of non-invasive oxygenation strategies in immunocompromised pa- tients with severe acute respiratory failure: a post-hoc analysis of a randomised trial. Lancet Respir Med 2016;4(8):646-652.

33. Azoulay E, Lemiale V, Mokart D, Nseir S, Argaud L, Pène F, et al. Effect of high-flow nasal oxygen vs standard oxygen on 28-day mortality in immunocompromised patients with acute respiratory failure: The HIGH randomized clinical trial. JAMA 2018;320(20): 2099-2107.

34. Duan J, Han X, Bai L, Zhou L, Huang S. Assessment of heart rate, acidosis, consciousness, oxygenation, and breathing frequency to predict noninvasive ventilation failure in hypoxemic patients. Intensive Care Med 2017;43(2):192-199.

35. Rodríguez A, Ferri C, Martin-Loeches I, Díaz E, Masclans JR, Gordo F, et al.; Grupo Español de Trabajo Gripe A Grave (GETGAG)/ Sociedad Española de Medicina Intensiva, Crítica y Unidades Coronarias (SEMICYUC) Working Group, 2009-2015 H1N1 SEMICYUC Working Group investigators. Risk factors for noninvasive ventilation failure in critically ill subjects with confirmed influenza infection. Respir Care 2017;62(10):1307-1315.

36. Hraiech S, Alingrin J, Dizier S, Brunet J, Forel JM, La Scola B, et al. Time to intubation is associated with outcome in patients with community-acquired pneumonia. PLoS One 2013;8(9):e74937.

37. Carteaux G, Lyazidi A, Cordoba-Izquierdo A, Vignaux L, Jolliet P, Thille AW, et al. Patient-ventilator asynchrony during noninvasive ventilation: a bench and clinical study. Chest 2012;142(2):367-376.

38. Lellouche F, Maggiore SM, Lyazidi A, Deye N, Taillé S, Brochard L. Water content of delivered gases during non-invasive ventilation in healthy subjects. Intensive Care Med 2009;35(6):987-995.

39. Branson RD, Gentile MA. Is humidification always necessary during noninvasive ventilation in the hospital? Respir Care 2010;55(2):209216; discussion 216.

40. Jones PG, Kamona S, Doran O, Sawtell F, Wilsher M. Randomized controlled trial of humidified high-flow nasal oxygen for acute respiratory distress in the emergency department: the HOT-ER study. Respir Care 2016;61(3):291-299.

41. Doshi P, Whittle JS, Bublewicz M, Kearney J, Ashe T, Graham R, et al. High-velocity nasal insufflation in the treatment of respiratory failure: a randomized clinical trial. Ann Emerg Med 2018;72(1):7383.e5.

42. Goligher EC, Slutsky AS. Not just oxygen? Mechanisms of benefit from high-flow nasal cannula in hypoxemic respiratory failure. Am J Respir Crit Care Med 2017;195(9):1128-1131.

43. Mauri T, Galazzi A, Binda F, Masciopinto L, Corcione N, Carlesso $\mathrm{E}$, et al. Impact of flow and temperature on patient comfort during respiratory support by high-flow nasal cannula. Crit Care 2018;22(1): 120.

44. Mauri T, Turrini C, Eronia N, Grasselli G, Volta CA, Bellani G, et al. Physiologic effects of high-flow nasal cannula in acute hypoxemic respiratory failure. Am J Respir Crit Care Med 2017;195(9): 1207-1215.

\section{Discussion}

Hill: Very nice job, Tom, you covered a lot of ground very well. I have a couple of comments on the risk factors that you listed for NIV failure. One is a $\mathrm{V}_{\mathrm{T}}>9.5 \mathrm{~mL} / \mathrm{kg}$. I agree that it is of concern based on studies we have seen recently, but the study by Carteaux et al ${ }^{1}$ is an association study, and you cannot conclude anything about causality. High $\mathrm{V}_{\mathrm{T}}$ values could be a marker of worse disease rather than a causal factor, and I think that we have to be careful about how the $\mathrm{V}_{\mathrm{Ts}}$ were measured. I think in that study that they used critical care ventilators with dual-limb circuits and that is a more accurate way of measuring $\mathrm{V}_{\mathrm{T}}$, but, if you read off a $\mathrm{V}_{\mathrm{T}}$ on a bi-level device, it can be inaccurate, especially in the face of nonintentional air leaks. The FLORALI trial ${ }^{2}$ targeted $V_{T}$ of $7-10 \mathrm{~mL} / \mathrm{kg}$ in their NIV group, and it was thus no surprise that their average $\mathrm{V}_{\mathrm{T}}$ was $9.2 \mathrm{~mL} / \mathrm{kg}$. Then, they speculated that that's why the mortality was higher in the NIV group. You could say that they stacked the study against NIV. They also didn't measure $\mathrm{V}_{\mathrm{T}}$ in their HFNC group, so we don't know for sure that their $\mathrm{V}_{\mathrm{T}}$ values were lower than those of subjects who used NIV. I wonder about your thoughts. 
Piraino: I agree. In the study by Carteaux et al, ${ }^{1}$ they explicitly said it should be tested in a randomized controlled trial, that it was just an association so they can't say this is fact. I also mentioned it's only something that can be done on a ventilator with an exhalation limb. One of the reasons why I wanted to bring this up is that many respiratory therapists don't pay attention to exhaled $V_{T}$ values during NIV, maybe because they are not used to seeing them on standalone NIV devices. The type of device determines whether it can be monitored, and both of these studies used ICU ventilators to monitor exhaled $\mathrm{V}_{\mathrm{T}}$. Yes, the mean $\mathrm{V}_{\mathrm{T}}$ in the FLORALI trial ${ }^{2}$ for the NIV group was $9.2 \mathrm{~mL} / \mathrm{kg}$ of predicted body weight, and the researchers purposefully targeted $7-10 \mathrm{~mL} / \mathrm{kg}$ of predicted body weight. But, with a mean pressure support level of $8 \mathrm{~cm} \mathrm{H}_{2} \mathrm{O}$, I think what it may suggest is subjects' inspiratory drive was perhaps excessive. As I mentioned, the sicker someone is and the lower his or her $\mathrm{P}_{\mathrm{aO}_{2}} / \mathrm{F}_{\mathrm{IO}_{2}}$, the more challenging it is to control $\mathrm{V}_{\mathrm{T}}$. I think in the future what we should probably do is somehow measure inspiratory drive during NIV, not by sticking catheters in them but perhaps noninvasively by looking at something like diaphragm-thickening fraction. This increased drive may be why, in all the previous studies, there's a high failure rate with patients who are hypoxemic.

Hill: I don't see any obvious reason why HFNC should reduce inspiratory drive any more than NIV. So it's possible we'll see the same $V_{T}$ effects in people using HFNC.

Piraino: There may be, and the impact might be transpulmonary pressure. So, with NIV, even with reduced effort, you still have positive pressure going up, and, with that effort, you have transpulmonary pressure that is significantly higher than it would be with HFNC.

Hill: With regard to $\mathrm{P}_{\mathrm{aO}_{2}} / \mathrm{F}_{\mathrm{IO}_{2}}$, you list $150-200 \mathrm{~mm} \mathrm{Hg}$ as a reason to watch patients on NIV closely and to be prepared to intubate. The question I have is it makes a difference whether you're talking about the $\mathrm{P}_{\mathrm{aO}} / \mathrm{F}_{\mathrm{IO}_{2}}$ at baseline or at hour 1 or 2 after NIV initiation. In the studies by Antonelli et al ${ }^{3,4}$ you showed an increase in $\mathrm{P}_{\mathrm{aO}_{2}} / \mathrm{F}_{\mathrm{IO}_{2}}$ to 150 $175 \mathrm{~mm} \mathrm{Hg}$ after the first hour of NIV is actually a favorable prognostic factor. Are you talking baseline or after an hour or two?

Piraino: If it's $<150 \mathrm{~mm} \mathrm{Hg}$ and you can't increase it to $>150 \mathrm{~mm} \mathrm{Hg}$ after $1 \mathrm{~h}$, I would consider that high risk. The $200 \mathrm{~mm} \mathrm{Hg}$ was at $1 \mathrm{~h}$ as well, but I think it's clear that the lower the $\mathrm{P}_{\mathrm{aO}_{2}} / \mathrm{F}_{\mathrm{IO}_{2}}$, the higher the risk, but 150$200 \mathrm{~mm} \mathrm{Hg}$ is not without risk. Also, I think it is important to not focus on just one parameter because there clearly are a lot more to look at.

Hill: Certainly, and I'm hearing you agree that it's the 1-2 $\mathrm{h}$ measurement is what we should focus on and how it compares with baseline. It should be going up.

Piraino: Exactly. Usually, as clinicians, we have that baseline blood gas, but I think that re-evaluation after 1-2 $\mathrm{h}$ and if it's increased from 110 to $150 \mathrm{~mm} \mathrm{Hg}$, I would still highly suspect that the patient may not tolerate NIV or that NIV may fail for him or her later and I would definitely start looking at the other factors. What is the breathing frequency, is his or her Glasgow coma scale score still intact, is he or she becoming hypotensive, and so forth.

\section{REFERENCES}

1. Carteaux G, Millán-Guilarte T, De Prost N, Razazi K, Abid S, Thille AW, et al. Failure of noninvasive ventilation for de novo acute hypoxemic respiratory failure: role of tidal volume. Crit Care Med 2016;44(2):282-290.

2. Frat JP, Thille AW, Mercat A, Girault C, Ragot S, Perbet S, et al.; FLORALI Study Group; REVA Network. High-flow oxygen through nasal cannula in acute hypoxemic respiratory failure. N Engl J Med 2015; 372(23):2185-2196

3. Antonelli M, Conti G, Moro ML, Esquinas A, Gonzalez-Diaz G, Confalonieri M, et al. Predictors of failure of noninvasive positive pressure ventilation in patients with acute hypoxemic respiratory failure: a multi-center study. Intensive Care Med 2001;27(11): 1718-1728.

4. Antonelli M, Conti G, Esquinas A, Montini L, Maggiore SM, Bello G, et al. A multiplecenter survey on the use in clinical practice of noninvasive ventilation as a first-line intervention for acute respiratory distress syndrome. Crit Care Med 2007;35(1):18-25.

This article is approved for Continuing Respiratory Care Education credit. For information and to obtain your CRCE

(free to AARC members) visit

www.rcjournal.com

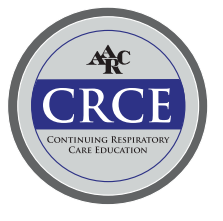

